\title{
Influence of Temperature and Oxidation-Reduction Potential on Hydrolysis of Swine Manure Wastewater
}

\author{
Worakan Chetawan, Kanyarat Saritpongteeraka, and Sumate Chaiprapat
}

\begin{abstract}
Thermal and micro-aeration pretreatments were applied to swine wastewater in order to improve hydrolysis of the substrate for biogas production. The experiments were carried out in 5-L reactors using $1 \%$ total solids concentration swine manure wastewater. Thermal pretreatments were performed at temperature of $30{ }^{\circ} \mathrm{C}$ (room temperature), $45^{\circ} \mathrm{C}$ and $55{ }^{\circ} \mathrm{C}$, while the micro-aeration pretreatments were operated at controlled ORP of -300 and $-420 \mathrm{mV}$. Results indicated that hydrolysis in terms of $\mathrm{SCOD}$ release was increased by $18.5 \%$ and $23.1 \%$ at 45 and $55{ }^{\circ} \mathrm{C}$, respectively (compared to $30^{\circ} \mathrm{C}$ ). TVFA also increased as a result of heightened acidogenesis. Micro-aeration could improve hydrolysis by $10.1 \%$ and $21.3 \%$, and TVFA by $7.23 \%$ and $12.87 \%$ (compared to non micro-aeration/uncontrolled ORP) at ORP -300 and $-420 \mathrm{mV}$, respectively. Both pretreatment methods attained high hydrolysis efficiency within $24 \mathrm{hr}$. However, too long of micro-aeration could lead to a loss of organic carbon thru oxidation as evidenced by the disappearing organic acids in the test reactors. Both thermal and micro-aeration pretreatments are environmental friendly and could be a simple solution to increase efficiency of biogas production by means of pre-hydrolysis.
\end{abstract}

Index Terms-Swine manure wastewater, hydrolysis, temperature, micro-aeration, pretreatment.

\section{INTRODUCTION}

Anaerobic digestion (AD) has been widely used for treating animal wastes and producing bioenergy. Swine manure, typically causing serious environmental problems, is a good substrate for biogas production [1]. However, it contains high solids, some of which are slowly biodegradable such as partly digested grain fiber. Hydrolysis step is generally a rate-limiting step of $\mathrm{AD}$, particularly for the solid substrate [2] that requires extensive hydrolysis to become soluble prior to being converted to biogas by the microorganisms. In staged AD, hydrolysis always takes place in first stage reactor. Thus, preparation of the substrate to a more soluble form can increase the subsequent digestion in the second stage [3].

Several studies reported various pretreatment methods to

Manuscript received September 5, 2019; revised January 12, 2020. This work was supported by Faculty of Engineering, Prince of Songkla University (PSU), PSU Graduate School, Thailand Research Fund (Grant No. RDG60500064), and Postdoctoral Fellowship from PSU.

W. Chetawan and K. Saritpongteeraka are with the Department of Civil Engineering, Faculty of Engineering, Prince of Songkla University, Songkhla, 90112, Thailand (e-mail: gun.rawo@gmail.com, kanya.sarit@gmail.com).

S. Chaiprapat is with the Department of Civil Engineering, Faculty of Engineering, Prince of Songkla University, Songkhla, Thailand, and PSU Energy Systems Research Institute (PERIN), Prince of Songkla University, Songkhla, 90112, Thailand (e-mail: sumate.ch@psu.ac.th). enhance hydrolysis (substrate solubilization), including physical, chemical, and biological means, or the combinations [3]. Since warm temperature has an effect on the activity of hydrolytic enzymes, controlling the temperature could then be used as a simple pretreatment scheme for hydrolysis [4]. Thermal pretreatment in thermophilic temperature (at $45-55^{\circ} \mathrm{C}$ ) could facilitate the destruction of degradable solids, enhance solubilization of carbohydrate, protein, lipid and fatty acids, all of which can be easily measured in terms of soluble oxygen demand (sCOD). Higher temperature is known to increase organic degradation but as pretreatment only hydrolysis is needed. Therefore, the influence of temperature levels and exposure time on the hydrolysis ability of swine manure is subject to further study where it may be a guideline for feed preparation to optimize the performance of the main digester

Due to the fact that anaerobic reaction is typically slow, the aerobic or facultative hydrolysis holds a kinetic advantage. The hydrolysis rate of aerobic or facultative bacteria could be much faster than the anaerobic ones [5], [6]. Thus, supplementing air to the swine manure slurry can also help improve substrate solubilization. Over aeration would, nevertheless, cause an oxidation and loss of substrate thru aerobic degradation.

Micro-aeration is a supply of a limited amount of air or oxygen and it can be precisely controlled by the oxidation-reduction potential value (ORP) [6]. Several studies reported the positive effective of micro-aeration on hydrolysis ability of protein and carbohydrate of various substrates such as sewage sludge, food waste, and agriculture wastes [5]: At a certain aeration rate, VFA production could also improve [7], in which ORP could be a good control parameter for this reaction.

In this study, hydrolysis activity of thermal and micro-aeration pretreated swine manure was evaluated in order to assess the effectiveness of each pretreatment method. Results from this study could suggest feasibility for a full-scale pre-hydrolysis reactor application.

\section{MethOD}

\section{A. Swine Manure}

Swine manure used in this study was taken from a local swine farm in Songkhla province, Thailand. Fresh manure was collected as solid and the total solids (TS) and volatile solids (VS) were $0.24 \mathrm{gTS} / \mathrm{g}_{\text {fresh }}$ and $0.18 \mathrm{gVS} / \mathrm{gTS}$. Raw manure was kept in a refrigerator at $4{ }^{\circ} \mathrm{C}$ until use. The swine manure wastewater (SM) was prepared from fresh manure dissolved in distilled water at TS concentration of $1 \%$. $\mathrm{pH}$, 
VFA, soluble COD (sCOD), total COD (TCOD) and ammonia of $1 \% \mathrm{SM}$ were $7.60,510 \mathrm{mg} / \mathrm{L}, 1,883 \mathrm{mg} / \mathrm{L}$, $10,736 \mathrm{mg} / \mathrm{L}$ and $72 \mathrm{mg} / \mathrm{L}$, respectively.

\section{B. Experimental Setup}

The reactors were made of cylinder glass $(6.25 \mathrm{~L}$ with working volume $5.0 \mathrm{~L}$ ), which was heated with a heat tape. The top of reactors was covered with a PVC lid connected with aeration tube with a submersible diffuser. ORP controller (350 pH/ORP/Temperature 1/8-DIN Transmitter, Cole-Parmer, USA) and temperature controller (AKT4R112200, Panasonic, Japan) were used to manipulate oxygen and temperature, respectively. This study is divided into 2 sets. The first set, effect of temperature, composed of 3 treatments run at 30,45 and $55^{\circ} \mathrm{C}$, all without ORP control. The second set, effect of ORP, composed of 3 treatments, micro-aeration for ORP $-300 \mathrm{mV},-420 \mathrm{mV}$ and uncontrolled, all at $30{ }^{\circ} \mathrm{C}$. The experiments were operated for $72 \mathrm{hr}$, sampling every $6 \mathrm{hr}$ in first $24 \mathrm{hr}$, and every $12 \mathrm{hr}$ until sCOD varied less than $10 \%$

\section{Analytical Methods}

$\mathrm{pH}$ was measured by $\mathrm{pH}$ meter (FiveEasy PlusTM, METTLER-TOLEDO, Germany). TS, VS, TCOD, sCOD were determined according to Standard Methods for the Examination of Water and Wastewater [8]. Samples were filtered through a $1.2 \mu \mathrm{m}$ pore glass microfiber filters $(\mathrm{GF} / \mathrm{C}$ Whatman) for $\mathrm{SCOD}$ measurement while a $0.22-\mu \mathrm{m}$ pore syringe filter Nylon (CHROM@SEP) was used to filter sample to analyze for volatile fatty acid concentration using gas chromatography (GC 7820 A, Agilent Technology, USA) with a flame ionization detector (FID) and a capillary column (19091N-133 HP- INNOWax, Agilent Technology, USA

\section{RESULTS AND DISCUSSION}

\section{A. ORP Profile}

The ORP profiles of $1 \%$ TS swine manure slurry under thermal and micro-aeration pretreatments are shown in Fig. 1. At the beginning, ORP of the swine manure wastewater was $48 \pm 7 \mathrm{mV}$ and rapidly decreased during the first 10 minutes. Without ORP control by micro-aeration, the ORP values at reaction temperature $30^{\circ} \mathrm{C}, 45^{\circ} \mathrm{C}$ and $55^{\circ} \mathrm{C}$ reached $-460,-500$ and $-524 \mathrm{mV}$, respectively at the end of experiment $(72 \mathrm{hr})$. While the initial ORP drop to zero was due to lowering dissolved oxygen (DO) in SM slurry, further drip to negative values were caused by fermentative microbial activities. It was also observed that at higher temperature, the reaction within the reactor appeared to be more reductive. The final ORP value confirmed that anaerobic fermentation occurred [6]. At this point, some organics were converted to biogas which was lost out of the liquid, defeating the purpose of pretreatment. When controlled by micro-aeration, ORP value dropped to $-300 \mathrm{mV}$ at $9 \mathrm{hr}$ and $-420 \mathrm{mV}$ at $14 \mathrm{hr}$ before they stabilized until the end of the experiment. The reactor content was maintained homogeneous to ensure an even reaction within the reactor. A simple ORP upper and lower limit was kept in a range of
+10 and $-10 \mathrm{mV}$. Minimal air was used for control, which would insignificantly affect the operating cost of the digester.

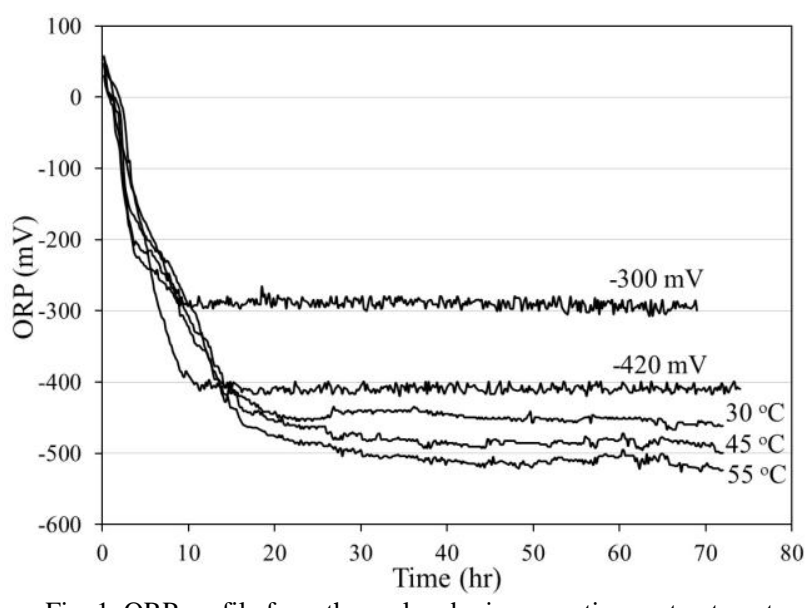

Fig. 1. ORP profile from thermal and micro-aeration pretreatment.

\section{B. $s C O D$ release}

Fig. 2(A) showed the comparative sCOD release as a result of thermal pretreatment. It was clear that higher temperature facilitates the hydrolysis of the organic matters in SM slurry. While sCOD was rather stable at $30{ }^{\circ} \mathrm{C}$, elevated levels of sCOD become apparent from the beginning at $45{ }^{\circ} \mathrm{C}$ and 55 ${ }^{\circ} \mathrm{C}$ until hour 24. sCOD concentrations increased from 1,843 $\mathrm{mg} / \mathrm{L}$ to 2,133 and $2,279 \mathrm{mg} / \mathrm{L}$, respectively, in $24 \mathrm{hr}$. The final sCOD concentration were 2,160 and 2,303 $\mathrm{mg} / \mathrm{L}$ for 45 ${ }^{\circ} \mathrm{C}$ and $55^{\circ} \mathrm{C}$, respectively. It is noted that after $24 \mathrm{hr}$, sCOD values of 45 and $55^{\circ} \mathrm{C}$ were not statistically different at $\alpha=0.05$. However, the final SCOD at the end of experiment (72 hr.) are significantly different among the three temperature levels $(\alpha=0.05)$. Results suggest that sCOD concentration corresponded to temperature increment, indicating a temperature assisted solubilization/hydrolysis [9]. Within a certain limit, higher temperature promoted higher microbial enzyme activities [3]. Thermophilic condition also reportedly enhanced the production and release of extracellular hydrolytic enzymes from hydrolytic bacteria and help compromise substrate structures.

Fig. 2(B) showed the sCOD release of micro-aeration pretreatment, all conducted at $30{ }^{\circ} \mathrm{C}$. The maximum sCOD concentration in this experiment was $2,173 \mathrm{mg} / \mathrm{L}$ at $15 \mathrm{hr}$ and $2,320 \mathrm{mg} / \mathrm{L}$ at $26 \mathrm{hr}$ at controlled ORP of $-300 \mathrm{mV}$ and -420 $\mathrm{mV}$, respectively. The uncontrolled set was stable while there were obvious changes in SCOD when micro-aeration ORP control was applied. Increment of sCOD can be explained by the higher hydrolytic activities by the fermentative bacteria. The environmental condition suitable for the facultative fermentative bacteria was created by the oxygen in air supplied. This slightly less reductive condition enhanced electron transportation mechanism and with some oxygen the redox balance could be maintained [6] while some organic matters could also be hydrolyzed by aerobic bacteria [10] Micro-aerobic condition aided aerobe and facultative hydrolytic bacteria growth rate [11]. The increment of enzyme concentration could hence promote higher hydrolysis rate [12]. However, final sCOD of ORP $-300 \mathrm{mV}$ and $-420 \mathrm{mV}$ dropped to 1,107 and $1,680 \mathrm{mg} / \mathrm{L}$, respectively. This phenomenon took place by oxidization of air excess [10] 
which would demerit the purpose of pretreatment. Virtually, no change of sCOD took place without micro-aeration. This suggest that the period of micro-aeration of $26 \mathrm{hr}$. would be sufficient.

Overall, the improvement from thermal pretreatment at 45 and $55{ }^{\circ} \mathrm{C}$ accounted for sCOD release of $+18.5 \%$ and $+23.1 \%$ while it was $10.0 \%$ and $21.3 \%$ under ORP control regime of $30{ }^{\circ} \mathrm{C}$ at $-300 \mathrm{mV}$ and $-420 \mathrm{mV}$, respectively. All of these pretreatments took no more than $26 \mathrm{hr}$ depending on the condition applied. This time duration fits well as a hydraulic detention time (HRT) of an equalization tank placed in front of the anaerobic digester.
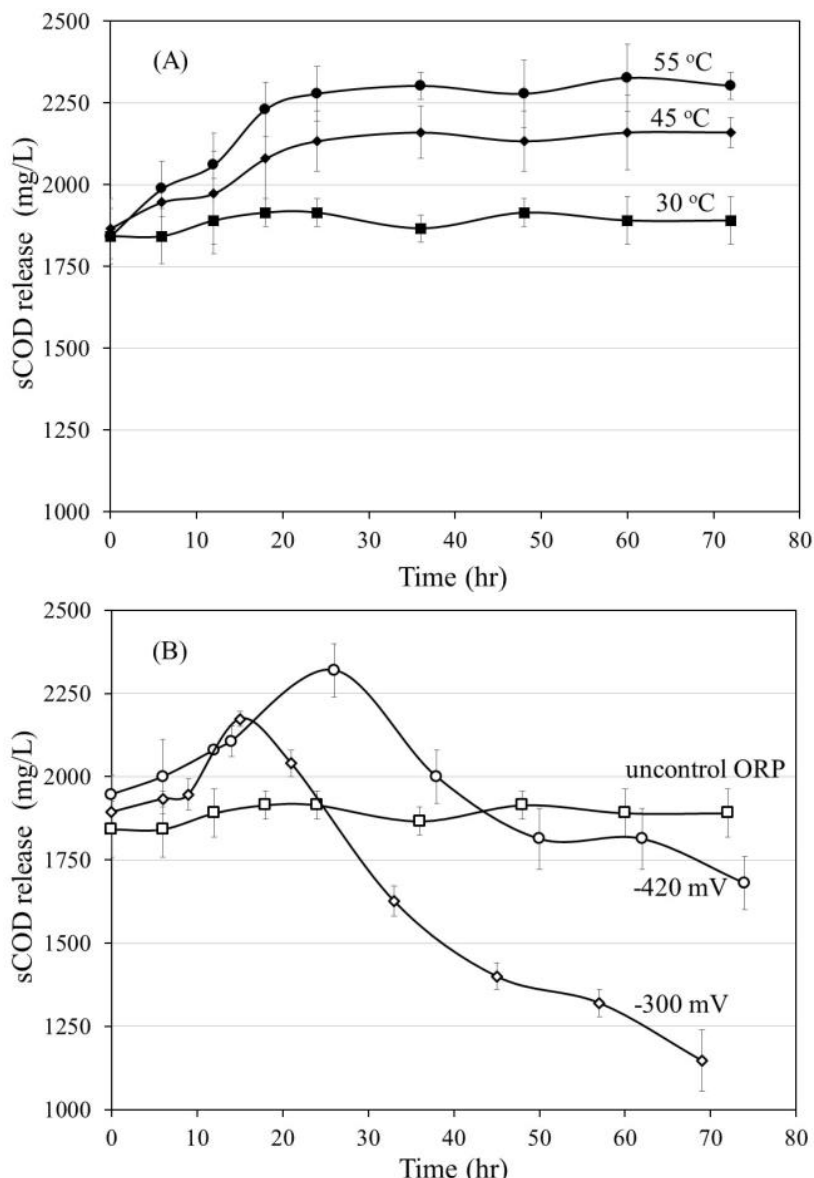

Fig .2. sCOD release from (A) thermal pretreatment; (B) micro-aeration pretreatment at a constant temperature of $30^{\circ} \mathrm{C}$.

\section{Volatile Fatty Acid Formation}

Changes in total volatile fatty acid (TVFA) level under thermal pretreatment are shown in Fig. 3A. The initial TVFA was around $510 \pm 20 \mathrm{mg} / \mathrm{L}$ as HAc. After exposing to temperature $45{ }^{\circ} \mathrm{C}$ and $55^{\circ} \mathrm{C}$ for $24 \mathrm{hr}$, TVFA increased to 610 and $628 \mathrm{mg} / \mathrm{L}$ as HAc, respectively, compared to 567 $\mathrm{mg} / \mathrm{L} \mathrm{HAc}$ at room temperature $\left(30^{\circ} \mathrm{C}\right)$. TVFA, however, continued to rise substantially to 638 and $687 \mathrm{mg} / \mathrm{L}$ as HAc for $45^{\circ} \mathrm{C}$ and $55^{\circ} \mathrm{C}$, while it was marginally increased to 587 $\mathrm{mg} / \mathrm{L}$ as $\mathrm{HAc}$ at $30{ }^{\circ} \mathrm{C}$. This was a result of continuous acidogenic reaction from the solubilized organic matters [9] even though sCOD remained constant after $24 \mathrm{hr}$ (Fig. 2A). However, the positive effect of temperature on acidogenesis reaction in this pretreatment stage was not so important since this reaction could be carried out within the main anaerobic digester. Moreover, higher acid concentration could cause higher corrosion to the pretreatment tank which in this case does not have sufficient buffer capacity as in the main digester.

When micro-aeration and ORP control strategy was implemented, TVFA concentration profiles were altered dramatically. There was a noticeable surge of TVFA concentration in ORP control sets (Fig. 3B) to around $15 \mathrm{hr}$ for ORP $-300 \mathrm{mV}$ and $26 \mathrm{hr}$ for ORP $-420 \mathrm{mV}$. After which, TVFA started to decrease. The maximum TVFA of $-300 \mathrm{mV}$ and $-420 \mathrm{mV}$ were 608 and $640 \mathrm{mg} / \mathrm{L}$ as HAc, respectively, versus $587 \mathrm{mg} / \mathrm{L}$ as HAc for the uncontrolled set which occurred at $72 \mathrm{hr}$. While the oxygen supply promoted higher hydrolytic microbial growth and increased enzyme activities from facultative bacteria in substrate [11], the very oxygen supply could also oxidize the simple organic acid molecules by aerobic bacteria when in excess. This caused TVFA oxidation to carbon dioxide gas $\left(\mathrm{CO}_{2}\right)$ and a loss of substrate for methane generation [13].

The benefit of thermal pretreatment at 45 and $55{ }^{\circ} \mathrm{C}$ is an enhancement of TVFA production of $+10.75 \%$ and $+17.03 \%$ over room temperature $\left(30{ }^{\circ} \mathrm{C}\right)$. Meanwhile, the controlled ORP of -300 and $-420 \mathrm{mV}$ showed the TVFA production was increased by $+7.23 \%$ and $+12.87 \%$ in shorter than $26 \mathrm{hr}$. Continued supply of oxygen was not recommended in this strategy.
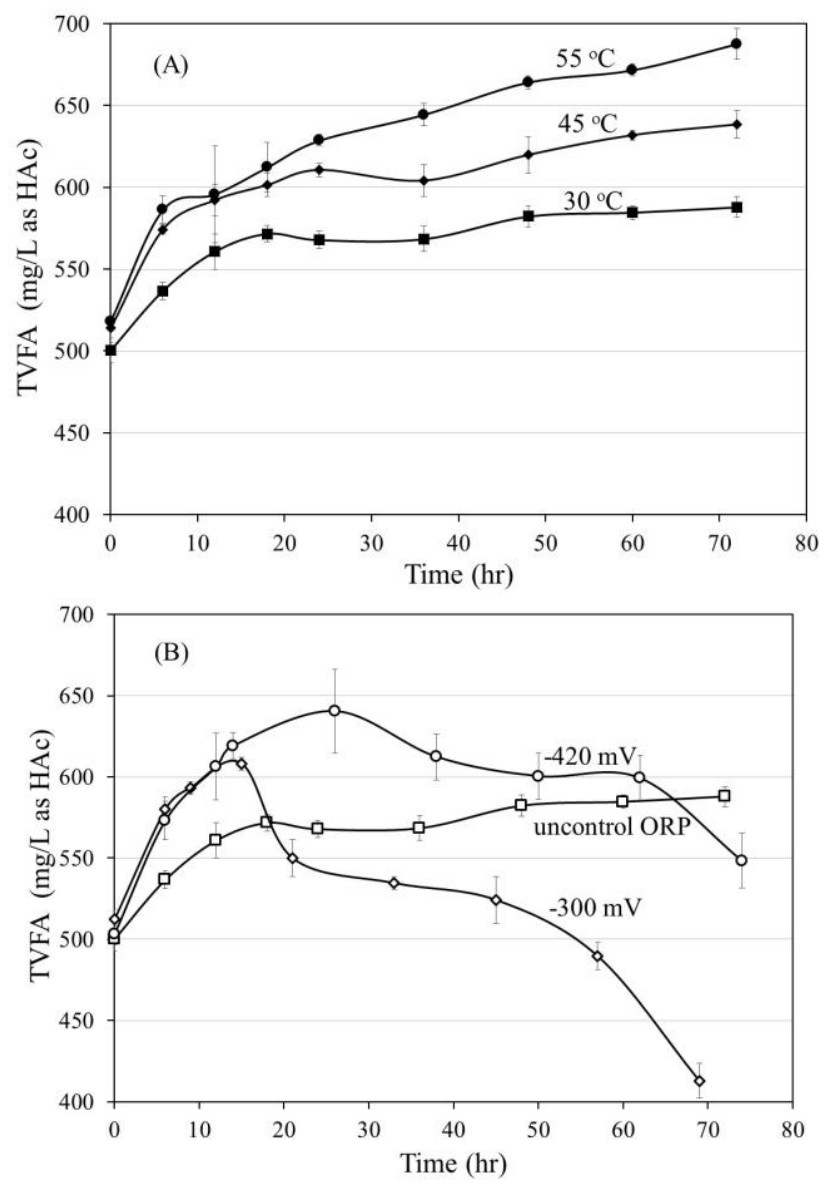

Fig .3. TVFA concentration from (A) thermal pretreatment; (B) micro-aeration pretreatment at $30^{\circ} \mathrm{C}$.

\section{D. $p H$ Change}

Fig. 4 showed $\mathrm{pH}$ changes of all thermal and micro-aeration pretreatments over time. $\mathrm{pH}$ decreased at a faster rate during the first $24 \mathrm{hr}$ at $0.019-0.029 \mathrm{unit} / \mathrm{hr}$ compared to $0.003-0.004$ unit/hr during 24-72 hr. pH drop 
corresponded well with the TVFA profiles since the acids produced were not degraded into biogas. Inevitable acidification in the thermal pretreatment tank deserves some precaution as it may corrode concrete or metal in contact with the liquid. At less than $24 \mathrm{hr}$, the lowest $\mathrm{pH}$ of all temperatures tested was 6.93 which does not require special acid protection lining.

In micro-aeration pretreatments (Fig. 4B), $\mathrm{pH}$ dropped to the minimum of 7.27 and 7.14 at ORP -300 and $-420 \mathrm{mV}$, respectively. The disappearance of TVFA (Fig. 3B) had lowered acidity in the liquid and our measurement on alkalinity was increased as a result of ammonification (releasing $\mathrm{NH}_{4}{ }^{+}$) of the protein and organic nitrogen in the swine manure [14], thus increasing liquid's buffer capacity. Meanwhile, $\mathrm{pH}$ dropped continuously to the final value of 6.93 in the non-micro-aeration (uncontrolled ORP) treatment.
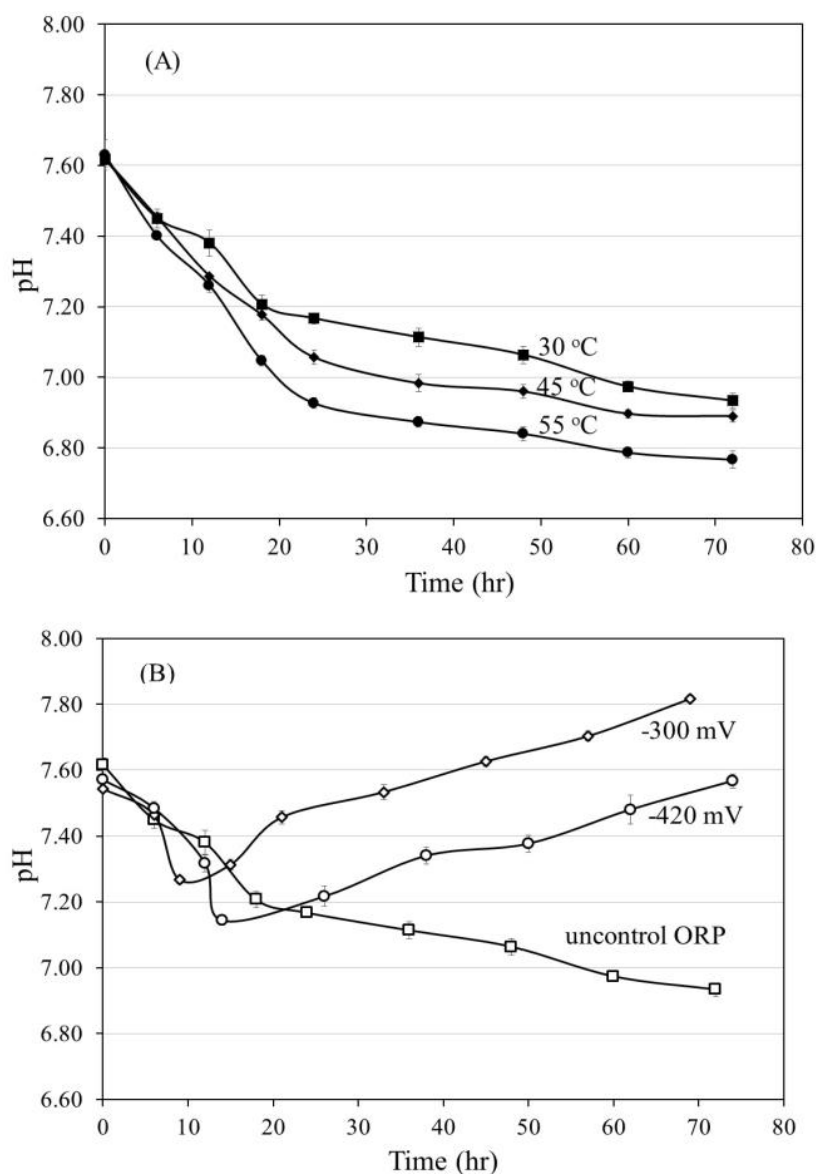

Fig. 4. pH change from (A) thermal pretreatment; (B) micro-aeration pretreatment at $30{ }^{\circ} \mathrm{C}$.

\section{CONCLUSION}

Thermal and micro-aeration pretreatment significantly increased hydrolysis and TVFA production rate. Highest substrate hydrolysis from both methods could accomplish within $24 \mathrm{hr}$. Although changes in characteristics of swine manure liquid can be directly used to determine the proper pre-hydrolysis operation, it is tedious task to perform. In thermal pretreatment, only hydraulic retention time (HRT) of the tank of $24 \mathrm{hr}$ can be set, while the heat source for pre-hydrolysis tank heating can be the waste heat from biogas engine or from production process. Micro-aeration could be optimally applied with the help of ORP controller and air blower. Precaution on over aeration should be exercised to prevent the loss of substrate to the main digester. Future work should focus on the possible synergistic interaction of the two parameters, and the least cost for upscaling the process control. Application on other digester substrates should be tested.

\section{CONFLICT OF INTEREST}

The authors declare no conflict of interest.

\section{AUTHOR CONTRIBUTION}

W. Chetawan conducted the research, analyzed the data and wrote the paper; all authors had approved the final version.

\section{ACKNOWLEDGMENT}

Authors would like to thank the Energy Systems Research Institute of Prince of Songkla University (PERIN) and SPM Feed Mill Co., Ltd for their administrative and technical supports of the work. The authors would also like to recognize the support for research facility at the Biogas and Biorefinery Research Laboratory, Faculty of Engineering of Prince of Songkla University.

\section{REFERENCES}

[1] D. J. Lee, J. S. Bae, and D. C. Seo, "Potential of biogas production from swine manure in South Korea," Applied Biological Chemistry, vol. 61, pp. 557-565, 2018

[2] V. Moset, E. Bertolini, A. Cerisuelo, M. Cambra, A. Olmos, and M Cambra-López, "Start-up strategies for thermophilic anaerobic digestion of pig manure," Energy, vol. 74, pp. 389-395, 2014.

[3] M. J. Odedina, B. Charnnok, K. Saritpongteeraka, and S. Chaiprapat, "Effects of size and thermophilic pre-hydrolysis of banana peel during anaerobic digestion, and biomethanation potential of key tropical fruit wastes," Waste Management, vol. 68, pp. 128-138, 2017.

[4] K. Luo, Q. Yang, X.-M. Li, G.-J. Yang, Y. Liu, D.-B. Wang, W. Zheng, and G.-M. Zeng, "Hydrolysis kinetics in anaerobic digestion of waste activated sludge enhanced by $\alpha$-amylase," Biochemical Engineering Journal, vol. 62, pp. 17-21, 2012.

[5] D. Botheju and R. Bakke, "Oxygen effects in anaerobic digestion-a review," The Open Waste Management Journal, vol. 4, pp. 1-19, 2011.

[6] D. Nguyen and S.K. Khanal, "A little breath of fresh air into an anaerobic system: How microaeration facilitates anaerobic digestion process," Biotechnology Advances, vol. 36, pp. 1971-1983, 2018.

[7] C. Sawatdeenarunat, S. Sung, and S. K. Khanal, "Enhanced volatile fatty acids production during anaerobic digestion of lignocellulosic biomass via micro-oxygenation," Bioresource Technology, vol. 237, pp. 139-145, 2017.

[8] APHA, Standard Methods for the Examination of Water and Wastewater, Washington, DC: American Public Health Association, 2005

[9] W. Arras, A. Hussain, R. Hausler, and S.R. Guiot, "Mesophilic, thermophilic and hyperthermophilic acidogenic fermentation of food waste in batch: Effect of inoculum source,"Waste Management, vol. 87, pp. 279-287, 2019.

[10] J.E. Johansen and R. Bakke, "Enhancing hydrolysis with microaeration," Water science and Technology, vol. 53, pp. 43-50, 2006.

[11] M. Zhu, F. Lü, L.-P. Hao, P.-J. He, and L.-M. Shao, "Regulating the hydrolysis of organic wastes by micro-aeration and effluent recirculation," Waste Management, vol. 29, pp. 2042-2050, 2009.

[12] D. Li, C. Jiao, W. He, Z. Yan, Y. Yuan, Z. Li, Y. Guo, and X. Liu, "Comparison of micro-aerobic and anaerobic fermentative hydrogen production from corn straw," International Journal of Hydrogen Energy, vol. 41, pp. 5456-5464, 2016.

[13] D. H. Zitomer and J. D. Shrout, "Feasibility and benefits of methanogenesis under oxygen-limited conditions," Waste Management, vol. 18, pp. 107-116, 1998. 
[14] A. Luo, J. Zhu, and P.M. Ndegwa, "Removal of carbon, nitrogen, and phosphorus in pig manure by continuous and intermittent aeration at low redox potentials," Biosystems Engineering, vol. 82, pp. 209-215, 2002.

Copyright $\odot 2020$ by the authors. This is an open access article distributed under the Creative Commons Attribution License which permits unrestricted use, distribution, and reproduction in any medium, provided the original work is properly cited (CC BY 4.0).

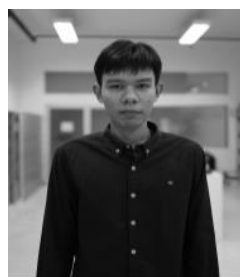

Worakan Chetawan is a master degree student and holds bachelor's degree in Environmental Engineering from Prince of Songkla University, Songkhla, Thailand. His master degree research is focusing on effect of temperature and oxidation-reduction potential (ORP) on digestibility and biogas production from pig farm wastewater.

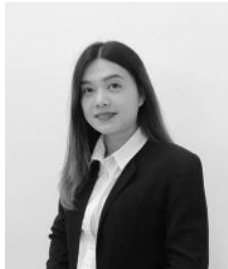

Kanyarat Saritpongteeraka received the Ph.D. degree in environmental management from Prince of Songkla University, Thailand in 2015.

She is currently a postdoctoral fellow at the Department of Civil Engineering, Faculty of Engineering, Prince of Songkla University, Songkhla, Thailand. Prior to joining PSU, she was a postdoctoral fellow at the Center of Excellence on Energy
Technology and Environmental, Postgraduate Education and Research Development Office (PERDO), Bangkok, Thailand.

Her main fields of interest include biogas production technology, biorefinery, and biomass pretreatment technology for solid biofuels and bioproducts.

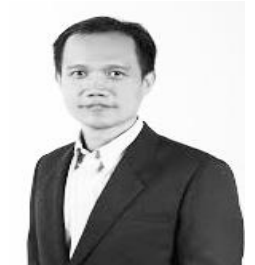

Sumate Chaiprapat received the Ph.D. degree in biological and agricultural engineering from North Carolina State University, USA in 2002. He is a professor at PSU Energy Systems Research Institute (PERIN) and lecturer in the Department of Civil Engineering, Faculty of Engineering, Prince of Songkla University, Songkhla, Thailand. $\mathrm{He}$ specialized in wastewater treatment, biogas technology and biorefinery of biomass into valuable products and biofuels. 